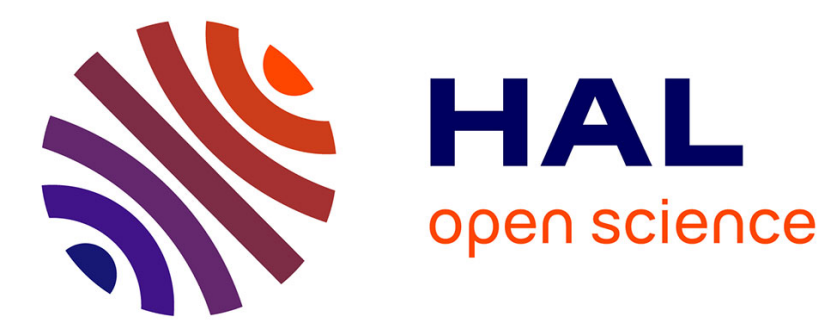

\title{
Quasi-geostrophic jet-like flow with obstructions
}

Michele Mossa, Roni Goldshmid, Maria-Eletta Negretti, Dan Liberzon, Joël

Sommeria, Donatella Termini, Francesca de Serio

\section{To cite this version:}

Michele Mossa, Roni Goldshmid, Maria-Eletta Negretti, Dan Liberzon, Joël Sommeria, et al.. Quasi-geostrophic jet-like flow with obstructions. Journal of Fluid Mechanics, 2021, 921, pp.A12. 10.1017/jfm.2021.501 . hal-03273210

\section{HAL Id: hal-03273210 https://hal.science/hal-03273210}

Submitted on 8 Sep 2021

HAL is a multi-disciplinary open access archive for the deposit and dissemination of scientific research documents, whether they are published or not. The documents may come from teaching and research institutions in France or abroad, or from public or private research centers.
L'archive ouverte pluridisciplinaire HAL, est destinée au dépôt et à la diffusion de documents scientifiques de niveau recherche, publiés ou non, émanant des établissements d'enseignement et de recherche français ou étrangers, des laboratoires publics ou privés. 


\title{
Quasi-geostrophic jet-like flow with obstructions
}

\author{
Michele Mossa ${ }^{1,2}$, Roni H. Goldshmid ${ }^{3}$, Dan Liberzon $^{3}$, M. Eletta Negretti ${ }^{4}$, \\ Joel Sommeria ${ }^{4}$, Donatella Termini ${ }^{5}$ and Francesca De Serio ${ }^{1,2, \dagger}$ \\ ${ }^{1}$ DICATECh, Polytechnic University of Bari, 70125 Bari, Italy \\ ${ }^{2}$ CoNISMa, 00196 Rome, Italy \\ ${ }^{3}$ Faculty of Civil and Environmental Engineering, The Technion, 32000 Haifa, Israel \\ ${ }^{4}$ Univ. Grenoble Alpes, CNRS, Grenoble INP, LEGI, 38000 Grenoble, France \\ ${ }^{5}$ Department of Engineering, University of Palermo, 90133 Palermo, Italy
}

Jet-like flows are ubiquitous in the atmosphere and oceans, and thus a thorough investigation of their behaviour in rotating systems is fundamental. Nevertheless, how they are affected by vegetation or, generally speaking, by obstructions is a crucial aspect which has been poorly investigated up to now. The aim of the present paper is to propose an analytical model developed for jet-like flows in the presence of both obstructions and the Coriolis force. In this investigation the jet-like flow is assumed homogeneous, turbulent and quasi-geostrophic, and with the same density as the surrounding fluid. Laws of momentum deficit, length scales, velocity scales and jet centreline are analytically deduced. These analytical solutions are compared with some experimental data obtained using the Coriolis rotating platform at LEGI-Grenoble (France), showing a good agreement.

Key words: jets, coastal engineering

\section{Introduction}

Jet-like flows dominate many environmental frameworks including large river mouths flowing into the ocean, nuclear plant discharges and even chimney smokes. Jets have been extensively studied in the simpler context of unobstructed flows in non-rotating systems (Smith \& Mungal 1998). These studies revealed the influence of the initial jet characteristics (e.g. nozzle shape, dimensions, flow rate and boundary conditions such as topography and bathymetry) and hydrodynamic features of the ambient current on the jet evolution. The co-flow and cross-flow release of jets were thoroughly examined as well (Antonia \& Bilger 1973; Mahesh 2013), while comprehensive reviews are provided by

$\dagger$ Email address for correspondence: francesca.deserio@poliba.it 


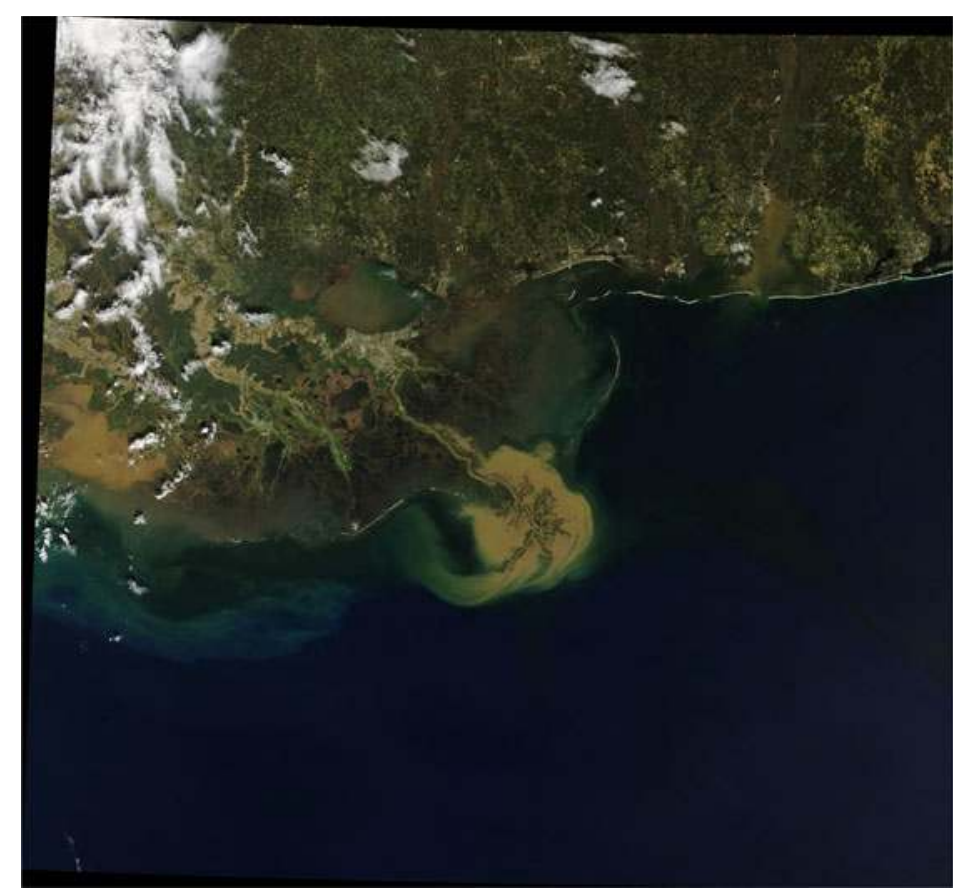

Figure 1. Image from NASA Earth Observatory by Joshua Stevens, using MODIS data from LANCE/EOSDIS Rapid Response. The image shows a sediment plume spilling into the Gulf of Mexico.

Rajaratnam (1976) and Fischer et al. (1979). Recently, jets interacting with waves have also been analysed (Barile et al. 2020).

Unobstructed jets affected by background rotation have been investigated in pioneering work by Gadgil (1971). The assumption was that the jet was laminar and quasi-geostrophic. Other studies, also assuming quasi-geostrophic jets, focused both on momentum jets (Lin \& Atkinson 1999) and on density-driven jets (Thomas \& Linden 2007). The former study found that rotation changes the orientation of turbulent eddies, affecting the energy cascading process; the latter found that mixing and entrainment depend on bottom slope, Froude and Reynolds numbers.

More recently, Mossa \& De Serio (2016) and Mossa et al. (2017) examined momentum jets travelling through a vegetation canopy. They analysed the turbulent integral length scales, turbulent diffusion coefficients and advective terms in the streamwise and spanwise directions for a turbulent jet entering an obstructed flow, and compared the results with those of the same jet in the absence of vegetation. In particular, the mimicked vegetation, arranged as a regular array of emergent rigid cylinders, induced an increased spanwise dispersion of the jet, acting as a blockage, and reduced at the same time the streamwise one. This finding is relevant, because it can be extended to unconventional ideas of jets through porous obstructions, such as the case of outflows from various sources spreading among oyster farms, wind farms and solar plants as well as aerial pesticides sprayed onto orchards or river jets flowing at mouths through bar deposits (Fagherazzi et al. 2015).

Based on previous considerations, it is clear that there is quite a good understanding of turbulent jets interacting with rotating frames and with vegetation in isolation. The mutual interaction of jet-like flows with obstructions (or macroroughness) and the Coriolis force remains inadequately investigated. It deserves a thorough understanding, especially 
(a)

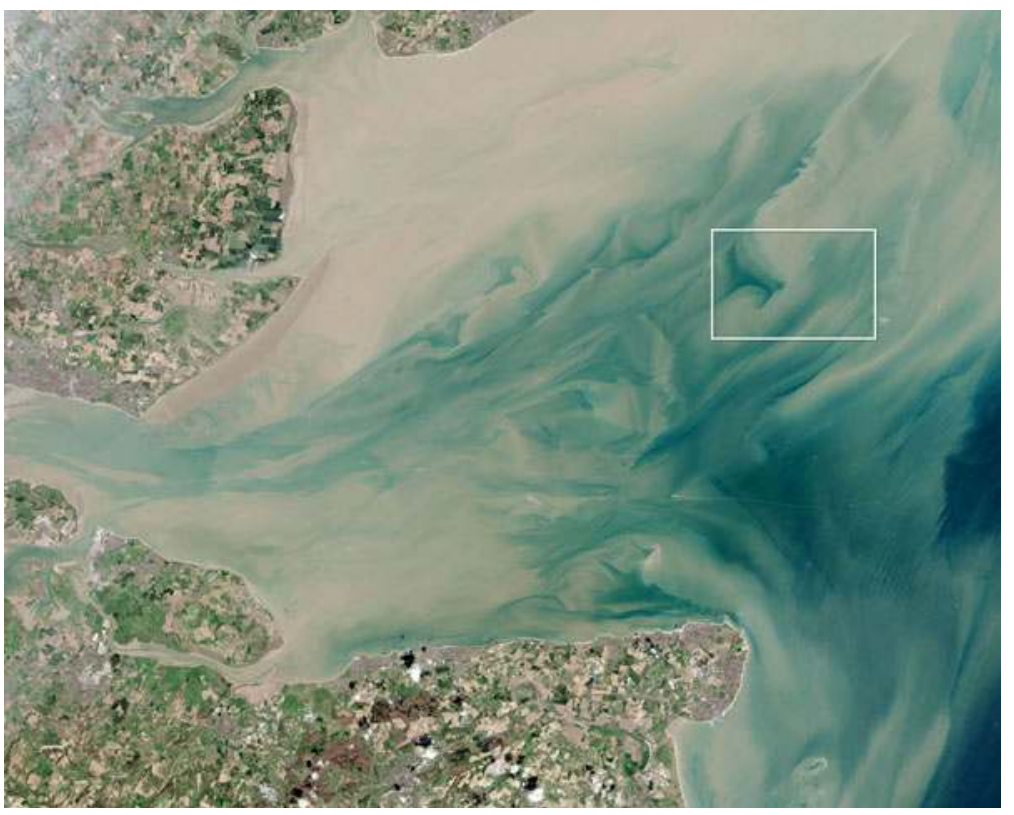

(b)

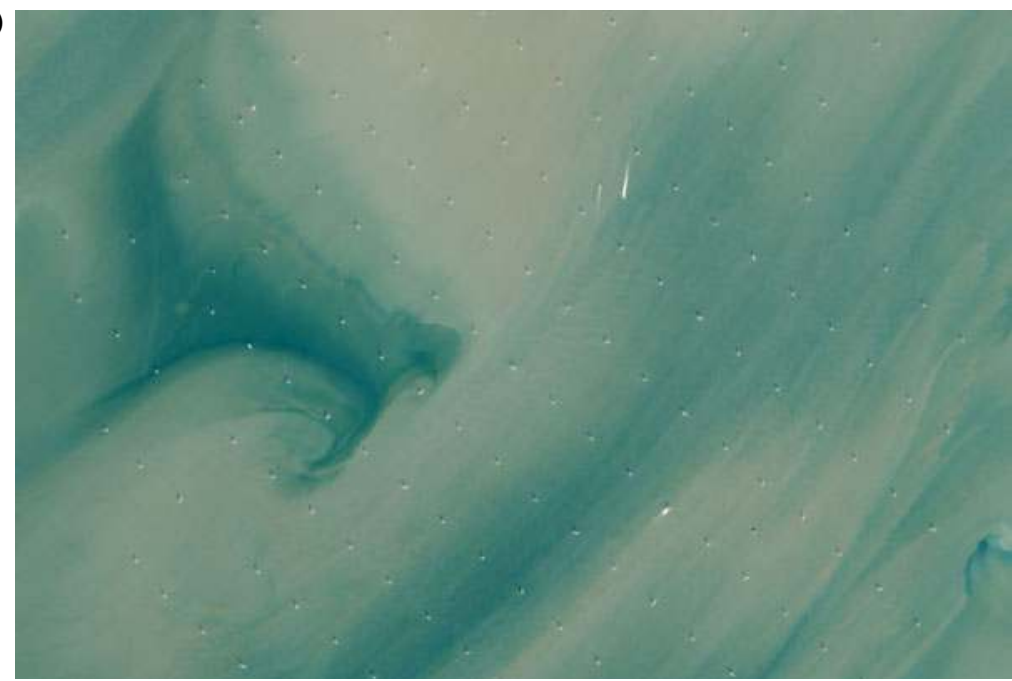

Figure 2. NASA Earth Observatory image by Jesse Allen and Robert Simmon, using Landsat data from the US Geological Survey, showing the offshore wind farm called London Array. (a) The offshore wind farm located in the Thames estuary (the stem array is in the rectangular zone). (b) Enlargement of the stem array of the wind farm.

considering that while density difference influences jet dynamics, for sufficiently large discharges (such as estuaries along the Atlantic Ocean coasts or in the Baltic Sea) the dynamics is mainly influenced by the inertial terms and rotation. Moreover, a further element influencing the spreading of jets is the presence of vegetation or, more generally, of obstructions in the form of macroroughness. As an example, figure 1 shows the Mississippi 
flood of 2018 with an evident sediment plume spilling into the Gulf of Mexico. It is also well known that vegetation is not just a static element of marine and fluvial ecosystems, but it interacts with different processes at different scales, e.g. blade scale, patch scale or canopy scale (Albayrak et al. 2011). Seagrasses form the foundation of many food webs and vegetation promotes biodiversity by creating different habitats with spatial heterogeneity in stream velocity (Kemp, Harper \& Crosa 2000). Marshes and mangroves reduce coastal erosion by damping waves and storm surges (Marois \& Mitsch 2015). These services are all influenced in some way by the flow field existing within and around the vegetated region. At the same time, vegetation itself affects flow structure and turbulence, which in turn impact the transport of sediments and scalars (White \& Nepf 2003, 2007, 2008; Tanino \& Nepf 2008; Nikora, Nikora \& O’Donoghue 2013). This type of interaction between flows and obstacles is also present at larger scales, such as in the case of the towers in wind farms. In this respect, figure 2(a) shows the world's largest offshore wind farm, located in the Thames estuary, where the River Thames meets the North Sea. This is the so-called London Array (figure 2b).

The present study aims at investigating the structure of a jet-like flow in a rotating system in the presence of obstacles. This study is of interest for environmental fluid mechanics, as well as for industrial applications, such as flows in mixers or rotating machinery. The jet-like flow is assumed planar, unbounded, turbulent and quasi-geostrophic, with the same density and temperature as the fluid environment where it is issued, and is characterized by a cross-length scale much smaller than the longitudinal one (Rajaratnam 1976; Jirka 1994).

The outline of the paper is the following. The theoretical model of a jet-like flow in a rotating system in the presence of obstacles is firstly illustrated. It focuses on length and velocity scales of the jets and their centre pathline, and on development of momentum deficit. The model is validated by comparing the theoretical results with those of experimental tests conducted at the Coriolis rotating platform (LEGI, France).

\section{Theoretical model}

\subsection{Formulation of the problem}

We consider an unbounded, plane and turbulent jet (Giger, Dracos \& Jirka 1991; Jirka 1994), released in an ambient flow with the same temperature, salinity and density, with the presence of obstructions and a background rotation $\Omega$. It is appropriate to specify that, assuming $\lambda$ the latitude and $\omega$ the rotation rate of the Earth, the Coriolis parameter is given by $2 \omega \sin \lambda=2 \Omega$. The top and bottom boundaries being assumed far from the jet, conventional Ekman theory is neglected. The origin of the coordinate system is at the centre of the jet release nozzle, the $x$ axis is the curvilinear axis coinciding with the jet main axis, the $y$ axis is normal to the $x$ axis (oriented in the direction opposed to that of jet radius of curvature $r$ ) and the $z$ axis is vertical and parallel to the rotation axis (as depicted in figure 3).

In the case of a plane turbulent jet issuing into an ambient fluid at rest with the presence of the Coriolis force and a cylinder array (figure 3), the Reynolds equations of motions are

$$
\begin{aligned}
\frac{\partial u}{\partial t} & +u \frac{\partial u}{\partial x}+v \frac{\partial u}{\partial y}+w \frac{\partial u}{\partial z}-2 \Omega v \\
& =-\frac{1}{\rho} \frac{\partial p}{\partial x}+v\left(\frac{\partial^{2} u}{\partial x^{2}}+\frac{\partial^{2} u}{\partial y^{2}}+\frac{\partial^{2} u}{\partial z^{2}}\right)-\left(\frac{\partial \overline{u^{\prime 2}}}{\partial x}+\frac{\partial \overline{u^{\prime} v^{\prime}}}{\partial y}+\frac{\partial \overline{u^{\prime} w^{\prime}}}{\partial z}\right)-\frac{1}{\rho} D_{x},
\end{aligned}
$$




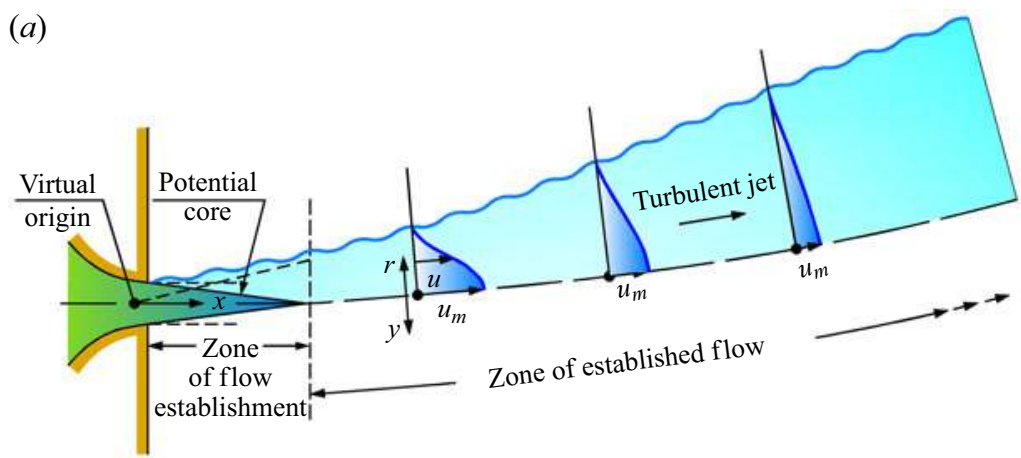

(b)

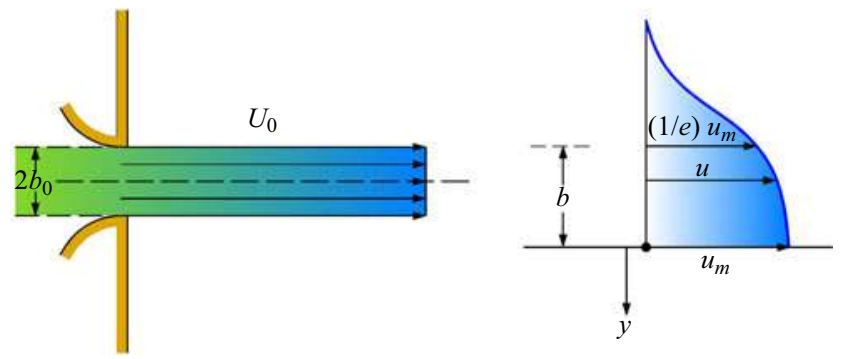

Figure 3. Sketch of a plane jet. (a) Plan view of the jet with a clockwise rotation. (b) Typical velocity profiles at the nozzle exit (on the left) and in the zone of established flow (on the right).

$$
\begin{aligned}
\frac{\partial v}{\partial t} & +\frac{U_{b}^{2}}{r}+u \frac{\partial v}{\partial x}+v \frac{\partial v}{\partial y}+w \frac{\partial v}{\partial z}+2 \Omega u \\
& =-\frac{1}{\rho} \frac{\partial p}{\partial y}+v\left(\frac{\partial^{2} v}{\partial x^{2}}+\frac{\partial^{2} v}{\partial y^{2}}+\frac{\partial^{2} v}{\partial z^{2}}\right)-\left(\frac{\partial \overline{u^{\prime} v^{\prime}}}{\partial x}+\frac{\partial \overline{v^{\prime 2}}}{\partial y}+\frac{\partial \overline{v^{\prime} w^{\prime}}}{\partial z}\right)-\frac{1}{\rho} D_{y} \\
\frac{\partial w}{\partial t} & +u \frac{\partial w}{\partial x}+v \frac{\partial w}{\partial y}+w \frac{\partial w}{\partial z} \\
& =-\frac{1}{\rho} \frac{\partial p}{\partial z}+v\left(\frac{\partial^{2} w}{\partial x^{2}}+\frac{\partial^{2} w}{\partial y^{2}}+\frac{\partial^{2} w}{\partial z^{2}}\right)-\left(\frac{\partial \overline{u^{\prime} w^{\prime}}}{\partial x}+\frac{\partial \overline{v^{\prime} w^{\prime}}}{\partial y}+\frac{\partial \overline{w^{\prime 2}}}{\partial z}\right)-\frac{1}{\rho} D_{z}
\end{aligned}
$$

where $u, v$ and $w$ and $u^{\prime}, v^{\prime}$ and $w^{\prime}$ are the time-averaged and fluctuating velocity components in the $x, y$ and $z$ directions, respectively, $p$ is the time-averaged pressure at any point, $v$ is the kinematic viscosity and $\rho$ is the mass density of both the jet and ambient fluid. The centripetal acceleration is $U_{b}^{2} / r$, with $U_{b}$ being the average of the longitudinal velocity in each cross-section. Furthermore, the drag forces in the $x, y$ and $z$ directions, i.e. the resistance due to the solid medium, sum of form and viscous drag over the stem, are $D_{x}, D_{y}$ and $D_{z}$, respectively; $t$ is the time variable and the overbar represents a time-average operator.

The continuity equation is

$$
\frac{\partial u}{\partial x}+\frac{\partial v}{\partial y}+\frac{\partial w}{\partial z}=0
$$


The relevant dimensionless parameters of the analysed flow are the Rossby number $R_{O}$ and the Reynolds number $R_{e}$, d e fi n e d a s

$$
R_{o}=\frac{U_{0}}{\Omega L_{x}}, \quad R_{e}=\frac{U_{0} b_{0}}{v},
$$

where $L_{x}$ is the jet-like longitudinal length scale and $U_{0}$ is the velocity at the jet nozzle (figure $3 b$ ).

It is worth noting that atmospheric and oceanographic flows can be considered as shallow with horizontal length scales much larger than their vertical length scales. Therefore they could be described using the shallow water equations. The Rossby number, which characterizes the strength of inertia compared to the strength of the Coriolis force, is equal to zero or is very small in the case of a geostrophic flow. In our quasi-geostrophic jet-like flow, the Rossby number is of order 1, so that the Coriolis and inertial forces are of similar magnitude. Below we consider only the zone of established flow (at $x>x_{0}$ ), where the longitudinal velocity distribution in each cross-section, i.e. the distribution of the $u$-velocity in the radial direction, has the same well-known Gaussian shape shown in figure 3 (Pope 2000). As shown in figure 3(b), at each cross-section the maximum longitudinal velocity component is $u_{m}$ and $b$ is the typical length scale, which is generally assumed as the distance from the jet centreline where the longitudinal velocity is $u=$ $u_{m} / e$, with $e$ being the Euler number, whose value is equal to $b_{0}$ at the jet origin. In the present model we consider the case of unbounded plane jets issuing into an ambient flow with a regular square array of emergent cylinders of uniform diameter $d$ and distance $s$ (figure 4). Another key parameter of the cylinder array used in the present paper is the frontal area per unit volume of the obstructions $a=n d$, which is equal to $d / s^{2}$ in the case of a periodic square array, where $n$ is the number of elements per unit planar area (Nepf 1999). The local variations of the velocity profiles detected in flows with obstacles (Ben Meftah \& Mossa 2016) are not considered here. However, the envelope cross-section velocity profile is taken into account to evaluate the effects of the presence of obstacles on the entire velocity profile.

The effect of obstructions is considered using the drag coefficient $C_{D}$ in the drag terms. As shown by Nepf (1999), various resistance laws of drag for flow in porous media can be derived. Particularly, in obstructed free-surface flows, the following quadratic form can be assumed:

$$
D_{i}=\frac{1}{2} \rho C_{D} a\left|u_{i}\right| u_{i}
$$

with $i=x, y, z$ (Kaimal \& Finnigan 1994). Since the flow is quasi-two-dimensional, we can approximate that $w=0, \partial / \partial z=0, \overline{u^{\prime} w^{\prime}}=0$ and $\overline{v^{\prime} w^{\prime}}=0$, and consider the mean flow as steady, $\partial / \partial t=0$. Furthermore, $u$ is generally much larger than $v$ in a large portion of the jet and velocity and stress gradients in the $y$ direction are much larger. Therefore, (2.1) and (2.2) become

$$
\begin{gathered}
u \frac{\partial u}{\partial x}+v \frac{\partial u}{\partial y}-2 \Omega v=-\frac{1}{\rho} \frac{\partial p}{\partial x}+v \frac{\partial^{2} u}{\partial y^{2}}-\frac{\partial \overline{u^{\prime 2}}}{\partial x}-\frac{\partial \overline{u^{\prime} v^{\prime}}}{\partial y}-\frac{1}{\rho} D_{x}, \\
0=-\frac{1}{\rho} \frac{\partial p}{\partial y}-\frac{\partial \overline{v^{\prime 2}}}{\partial y}-\frac{1}{\rho} D_{y}-2 \Omega u-\frac{U_{b}^{2}}{r}
\end{gathered}
$$




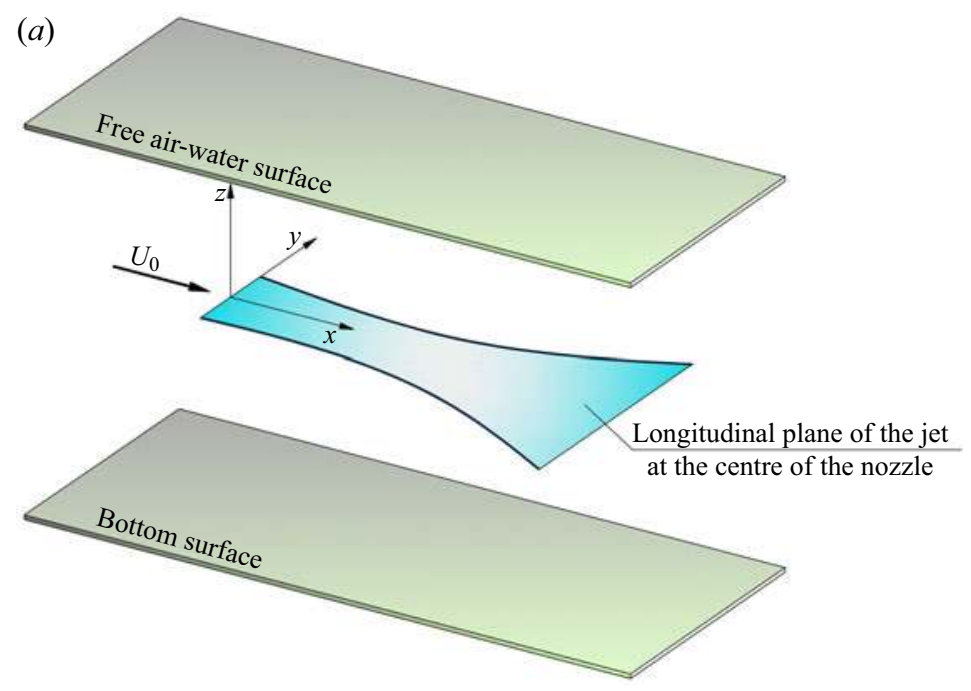

(b)

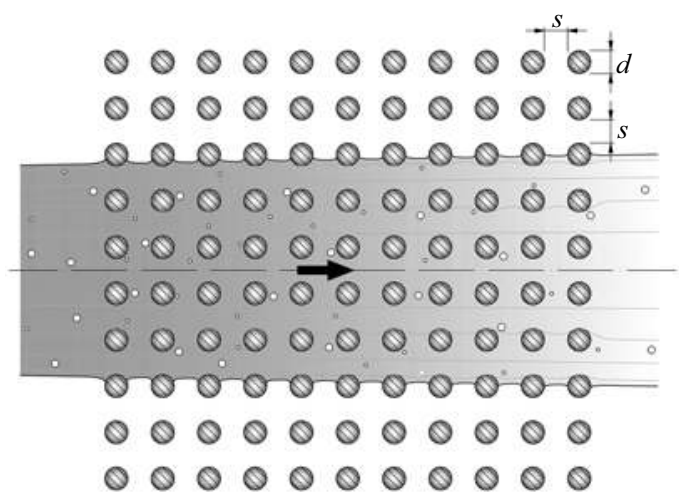

Figure 4. Sketch of the analysed plane jet. (a) Unbounded jet-like flow. (b) Plan view of the jet with the cylinder array.

Assuming $\mathscr{B}$ as the nominal outer boundary of the jet where $u$ is close to 0 , it is possible to write

$$
\mathscr{B}=\mathscr{C}_{b} b,
$$

where $\mathscr{C}_{b}$ is a constant. Integrating (2.8), with $P$ as the pressure outside the jet and assuming the radius of curvature sufficiently large to have symmetric/antisymmetric conditions for both sides of the jet, we get

$$
p=P-\rho \overline{v^{\prime 2}}-\int_{0}^{\mathscr{B}}\left(2 \rho \Omega u+D_{y}\right) \mathrm{d} y .
$$

Differentiating (2.10) with respect to $x$ and using it in (2.7), we get

$$
\begin{aligned}
u \frac{\partial u}{\partial x}+v \frac{\partial u}{\partial y}-2 \Omega v= & -\frac{1}{\rho} \frac{\mathrm{d} P}{\mathrm{~d} x}+v \frac{\partial^{2} u}{\partial y^{2}}-\frac{\partial \overline{u^{\prime} v^{\prime}}}{\partial y}-\frac{\partial}{\partial x}\left(\overline{u^{\prime 2}}-\overline{v^{\prime 2}}\right) \\
& -\frac{1}{\rho}\left(D_{x}+\frac{\mathrm{d}}{\mathrm{d} x} \int_{0}^{\mathscr{B}} D_{y} \mathrm{~d} y+\frac{\mathrm{d}}{\mathrm{d} x} \int_{0}^{\mathscr{B}} 2 \rho \Omega u \mathrm{~d} y\right) .
\end{aligned}
$$


As shown by Mossa et al. (2017) and De Serio et al. (2018), assuming that

$$
D_{x} \gg \frac{\mathrm{d}}{\mathrm{d} x} \int_{0}^{\mathscr{B}} D_{y} \mathrm{~d} y
$$

we obtain

$$
\begin{aligned}
u \frac{\partial u}{\partial x}+v \frac{\partial u}{\partial y}-2 \Omega v & =-\frac{1}{\rho} \frac{\mathrm{d} P}{\mathrm{~d} x}+v \frac{\partial^{2} u}{\partial y^{2}}-\frac{\partial \overline{u^{\prime} v^{\prime}}}{\partial y}-\frac{1}{\rho} D_{x}-2 \Omega\left(\frac{\mathrm{d}}{\mathrm{d} x} \int_{0}^{\mathscr{B}} u \mathrm{~d} y\right) \\
& =-\frac{1}{\rho} \frac{\mathrm{d} P}{\mathrm{~d} x}+v \frac{\partial^{2} u}{\partial y^{2}}-\frac{\partial \overline{u^{\prime} v^{\prime}}}{\partial y}-\frac{1}{\rho} D_{x}-2 \Omega v_{e}
\end{aligned}
$$

where

$$
v_{e}=\frac{\mathrm{d}}{\mathrm{d} x} \int_{0}^{\mathscr{B}} u \mathrm{~d} y
$$

is the so-called entrainment velocity, which can be written as

$$
v_{e}=\alpha_{e} u_{m}
$$

with $\alpha_{e}$ the entrainment/detrainment coefficient (Rajaratnam 1976; Mossa \& De Serio 2016). Observing that the laminar and turbulent stresses are, respectively,

$$
\left\{\begin{array}{l}
\tau_{l}=\mu \frac{\partial u}{\partial y} \\
\tau_{t}=-\rho \overline{u^{\prime} v^{\prime}}
\end{array}\right.
$$

and considering that $\tau_{t}$ is much larger than $\tau_{l}$ for the flows here considered and the gradient of pressure is null along the horizontal trajectories in geostrophic flows, which means the trajectories must take place along isochoric lines, we get

$$
u \frac{\partial u}{\partial x}+v \frac{\partial u}{\partial y}-2 \Omega v=\frac{1}{\rho} \frac{\partial \tau_{t}}{\partial y}-\frac{1}{\rho} D_{x}-2 \Omega v_{e} .
$$

Integration of (2.17) gives

$$
\rho \int_{0}^{\mathscr{B}} u \frac{\partial u}{\partial x} \mathrm{~d} y+\rho \int_{0}^{\mathscr{B}} v \frac{\partial u}{\partial y} \mathrm{~d} y-\int_{0}^{\mathscr{B}} \frac{\partial \tau_{t}}{\partial y} \mathrm{~d} y=-\int_{0}^{\mathscr{B}}\left(D_{x}+2 \rho \Omega v_{e}-2 \rho \Omega v\right) \mathrm{d} y,
$$

which becomes

$$
\frac{1}{2} \frac{\mathrm{d}}{\mathrm{d} x} \int_{0}^{\mathscr{B}} \rho u^{2} \mathrm{~d} y+\rho\left(|u v|_{y=0}^{y=\mathscr{B}}-\int_{0}^{\mathscr{B}} u \frac{\partial v}{\partial y} \mathrm{~d} y\right)=-\int_{0}^{\mathscr{B}}\left(D_{x}+2 \rho \Omega v_{e}-2 \rho \Omega v\right) \mathrm{d} y .
$$

Using the continuity equation (2.4), we obtain

$$
\frac{\mathrm{d}}{\mathrm{d} x} \int_{0}^{\mathscr{B}} \rho u^{2} \mathrm{~d} y=-\int_{0}^{\mathscr{B}}\left(D_{x}+2 \rho \Omega v_{e}-2 \rho \Omega v\right) \mathrm{d} y .
$$

If we write

$$
D_{x}=\frac{1}{2} \rho C_{D} a u^{2}
$$


we obtain that

$$
\frac{\mathrm{d} \mathscr{M}(x)}{\mathrm{d} x}=\frac{\mathrm{d}}{\mathrm{d} x} \int_{0}^{\mathscr{B}} u^{2} \mathrm{~d} y=-\frac{1}{2} C_{D} a \int_{0}^{\mathscr{B}} u^{2} \mathrm{~d} y-2 \Omega v_{e} \mathscr{B}+\int_{0}^{\mathscr{B}} 2 \Omega v \mathrm{~d} y,
$$

where $\mathscr{M}(x)$ is half the kinematic momentum flux in each cross-section. It is reasonable to assume that the trend of the $v$-velocity component along $y$ should be antisymmetric with respect to the jet axis (Goertler 1942). The last two terms of the right-hand side of (2.22) are overall responsible for a momentum decrease due to the jet rotation and, using a scale analysis (Tennekes \& Lumley 1972), they are similar. Therefore, it is reasonable to write that

$$
-2 \Omega v_{e} \mathscr{B}+\int_{0}^{\mathscr{B}}(2 \Omega v) \mathrm{d} y=-2 \chi_{v e} \Omega v_{e} \mathscr{B},
$$

where $\chi_{v e}$ is an empirical coefficient.

\subsection{Velocity and cross-length scales}

In the zone of established flow of a turbulent plane jet, the velocity distribution is similar (Rajaratnam 1976; Barile et al. 2020), so that

$$
\frac{u}{u_{m}}=f(\eta)
$$

with $\eta=y / b$.

Assuming power forms for $u_{m}$ and $b$ :

$$
\left\{\begin{array}{l}
b \propto x^{\phi} \Rightarrow b=\mathscr{F}_{1} x^{\phi} \\
u_{m} \propto x^{\psi} \Rightarrow u_{m}=\mathscr{F}_{2} x^{\psi}
\end{array}\right.
$$

where $\phi$ and $\psi$ are unknown exponents to be found. Equation (2.25) is valid for the zone of established flow.

By the change of variable $y=\eta / b$, since for $y=0$ we have $\eta=0$, and for $y=\mathscr{B}$ we get $\eta=y / b=\mathscr{B} / b=\mathscr{C}_{b}$, it follows that

$$
\frac{\mathrm{d}}{\mathrm{d} x} \int_{0}^{\mathscr{C}_{b}} u_{m}^{2} f^{2} b \mathrm{~d} \eta=-\frac{1}{2} C_{D} a \int_{0}^{\mathscr{C}_{b}} u_{m}^{2} f^{2} b \mathrm{~d} \eta-2 \Omega \chi_{v e} v_{e} \mathscr{B}
$$

or, analogously,

$$
\frac{\mathrm{d}}{\mathrm{d} x}\left(u_{m}^{2} b \int_{0}^{\mathscr{C}_{b}} f^{2} \mathrm{~d} \eta\right)=-\frac{1}{2} C_{D} a u_{m}^{2} b \int_{0}^{\mathscr{C}_{b}} f^{2} \mathrm{~d} \eta-2 \Omega \chi_{v e} v_{e} \mathscr{B} .
$$

Considering that

$$
\int_{0}^{\mathscr{C}_{b}} f^{2} \mathrm{~d} \eta=\text { const. }
$$

equation (2.27) can be rewritten as

$$
\frac{\mathrm{d}}{\mathrm{d} x}\left(u_{m}^{2} b\right)=-\frac{1}{2} C_{D} a b u_{m}^{2}-\frac{2 \Omega \chi_{v e} v_{e} \mathscr{B}}{\int_{0}^{\mathscr{C}_{b}} f^{2} \mathrm{~d} \eta},
$$


i.e.

$$
2 \psi+\phi=-\frac{1}{2} C_{D} a x-\frac{2 \Omega \chi_{v e} \alpha_{e} \mathscr{C}_{b} x^{1-\psi}}{\int_{0}^{\mathscr{C}_{b}} f^{2} \mathrm{~d} \eta} .
$$

From dimensional considerations it is possible to write that

$$
\frac{\tau}{\rho u_{m}^{2}}=g(\eta)
$$

Considering (2.24) and (2.31), denoting the derivatives with a prime symbol, we have

$$
f^{\prime}=\frac{\mathrm{d} f}{\mathrm{~d} \eta}, \quad g^{\prime}=\frac{\mathrm{d} g}{\mathrm{~d} \eta}, \quad b^{\prime}=\frac{\mathrm{d} b}{\mathrm{~d} x}, \quad u_{m}^{\prime}=\frac{\mathrm{d} u_{m}}{\mathrm{~d} x},
$$

and therefore we obtain

$$
\begin{gathered}
u \frac{\partial u}{\partial x}=u_{m} u_{m}^{\prime} f^{2}-\frac{u_{m}^{2} b^{\prime}}{b} \eta f f^{\prime} \\
v \frac{\partial u}{\partial y}=\frac{u_{m}^{2} b^{\prime}}{b}\left(\eta f f^{\prime}-f^{\prime} \int_{0}^{\eta} f \mathrm{~d} \eta\right)-u_{m} u_{m}^{\prime} f^{\prime} \int_{0}^{\eta} f \mathrm{~d} \eta \\
\frac{1}{\rho} \frac{\partial \tau}{\partial y}=\frac{u_{m}^{2}}{b} g^{\prime}, \\
-\frac{1}{\rho} D_{x}=-\frac{1}{2} C_{D} a u_{m}^{2} f^{2}, \\
-2 \Omega v_{e}=-2 \Omega \alpha_{e} u_{m} .
\end{gathered}
$$

Substituting (2.33), (2.34), (2.35) and (2.36) into (2.17), we obtain

$$
\begin{aligned}
g^{\prime}= & \frac{b u_{m}^{\prime}}{u_{m}}\left(f^{2}-f^{\prime} \int_{0}^{\eta} f \mathrm{~d} \eta\right)-b^{\prime}\left(\eta f^{\prime}-\eta f f^{\prime}+f^{\prime} \int_{0}^{\eta} f \mathrm{~d} \eta\right) \\
& +\frac{1}{2} C_{D} a b f^{2}+2 \chi_{v e} \Omega \alpha_{e} u_{m} .
\end{aligned}
$$

Since $g^{\prime}$ is a function of only $\eta$, the right-hand side should also be a function of only $\eta$ (Mossa et al. 2017; Barile et al. 2020). Particularly, from the first two terms on the right-hand side, it is possible to write

$$
\left\{\begin{array}{l}
\frac{b u_{m}^{\prime}}{u_{m}} \propto x^{\phi-1} \\
b^{\prime} \propto x^{\phi-1}
\end{array}\right.
$$

and therefore

$$
\phi=1
$$

i.e.

$$
b=\mathscr{F}_{1} \cdot x .
$$

In the present study we will consider jets with

$$
b=\mathscr{O}(n \cdot s),
$$

with $n=\mathscr{O}\left(10-10^{2}\right)$. In other words, referring to figure $4(b)$, we are considering the case where $d / s=\mathscr{O}\left(10^{-1}-1\right), b / d=\mathscr{O}\left(10-10^{2}\right), b / s=\mathscr{O}\left(10-10^{2}\right)$, such as that shown by Mossa et al. (2017). 
Therefore, it is possible to write

$$
b=\mathscr{F}_{1} x^{\phi}=\mathscr{O}((10 \div 100) \cdot s) .
$$

The order of magnitude of $b$ changes when it becomes

$$
10 b=10 \mathscr{F}_{1} x^{\phi}=\mathscr{O}((100 \div 1000) \cdot s),
$$

i.e. when $x^{\phi}$ increases by an order of magnitude or more. Therefore, $b$ has the same order of magnitude between two values of $x$, i.e. from $x_{1}$ to $x_{2}>x_{1}$, when

$$
\frac{x_{2}^{\phi}}{x_{1}^{\phi}}<\mathscr{O}(10) \text {. }
$$

Since in the analysed case $\phi=1$, it is possible to write that

$$
x_{1}, x_{2}=\mathscr{O}(n \cdot s) \quad \text { with } n \geqslant 10-100 .
$$

Furthermore, the rotation rate of the Earth $\Omega$ is equal to $7.2921 \times 10^{-5} \mathrm{rad} \mathrm{s}^{-1}$. It can be calculated as $2 \pi / T \operatorname{rad~s}^{-1}$, where $T$ is the rotation period of the Earth which is one sidereal day.

Therefore, along a longitudinal distance between $x_{1}$ and $x_{2}$ satisfying (2.43), equation (2.39) becomes

$$
\begin{aligned}
g^{\prime} \approx & \frac{b u_{m}^{\prime}}{u_{m}}\left(f^{2}-f^{\prime} \int_{0}^{\eta} f \mathrm{~d} \eta\right) \\
& -b^{\prime}\left(\eta f^{\prime}-\eta f f^{\prime}+f^{\prime} \int_{0}^{\eta} f \mathrm{~d} \eta\right)+\frac{1}{2} C_{D} \frac{d}{s^{2}} n s f^{2}+O\left(10^{-5}\right),
\end{aligned}
$$

where the third term of the right-hand side can be considered approximately constant in the described limits. With these considerations in mind and using (2.39) and (2.30), it is possible to conclude that

$$
\left\{\begin{array}{l}
\phi=\mathscr{O}(1) \\
\psi=\mathscr{O}\left(-\frac{1}{2}\right)-\frac{1}{4} C_{D} a x=\mathscr{O}\left(-\frac{1}{2}\right)-\frac{1}{4} C_{D} \frac{d}{s^{2}} x=C_{p}\left(-\frac{1}{2}-\frac{1}{4} C_{D} \frac{d}{s^{2}} x\right),
\end{array}\right.
$$

where, therefore, $C_{p}$ must have an order of magnitude of 1 .

The $x$ coordinate was previously considered as a curvilinear one. We analyse the theoretical model description of the jet each time addressing a relatively small range $x=\left[x_{1}, x_{2}\right]>x_{0}$ defined by the order of magnitude of $b$. With the change of order of magnitude of $b$, as we move along the jet axis, a new region is defined. Figure 5 shows the described divisions into regions, where $X$ and $Y$ are the axes of a Cartesian coordinate system (Barile et al. 2020).

This means that making the laws of $b$ and $u_{m}$ (equation (2.25)) dimensionless, we have

$$
\begin{aligned}
\frac{b}{b_{0}} & =C_{1}\left(\frac{x}{x_{0}}\right)^{\phi}+C_{2}, \\
\frac{u_{m}}{U_{0}} & =C_{3}\left(\frac{x^{\psi}}{x_{0} \psi_{0}}\right)+C_{4},
\end{aligned}
$$

where $\psi_{0}$ is the value of $\psi$ for $x=x_{0}$. It is reasonable to assume that the coefficients are a function of the range of $x$. In other words, the structures of the laws of $b$ and $u_{m}$ remain the same, but the coefficients can vary between the ranges and must be obtained from experiments. 


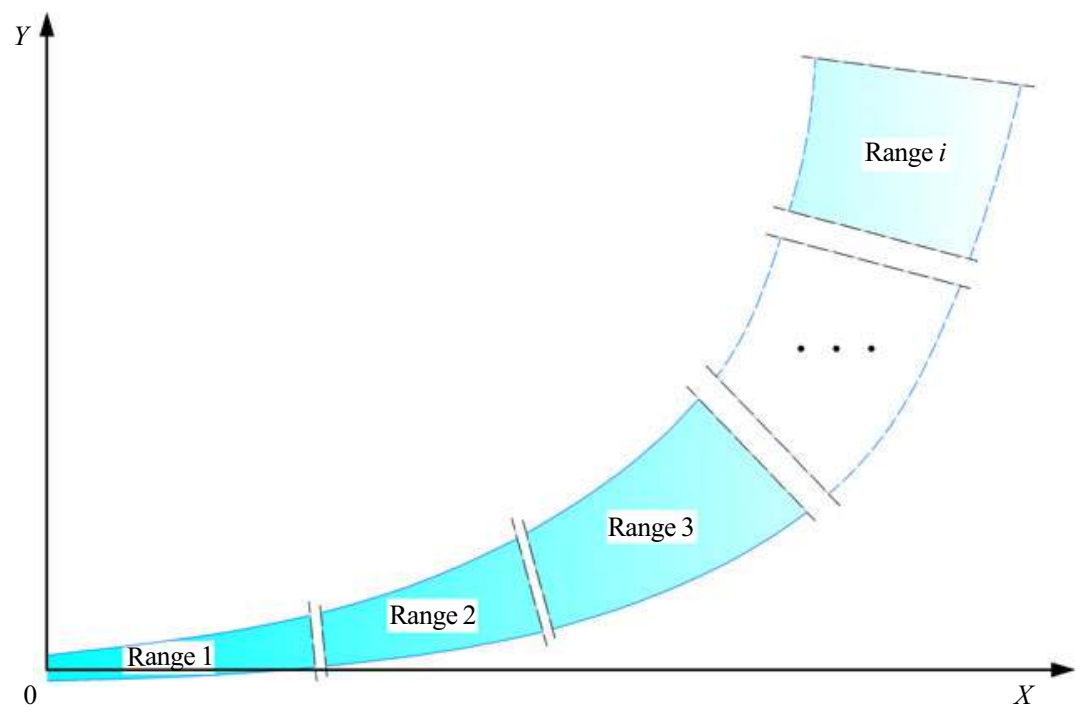

Figure 5. Regions of the jet where, as a fist approximation, the order of magnitude of $b$ is constant.

\subsection{The momentum flux deficit}

Considering (2.9), (2.15) and (2.25), we have the following equation in terms of scale analysis:

$$
-2 \chi_{v e} \Omega v_{e} \mathscr{B}=-2 \Omega \chi_{v e} \mathscr{C}_{b} \mathscr{F}_{1} x^{\phi} \alpha_{e} \mathscr{F}_{2} x^{\psi} \text {. }
$$

Therefore, integrating (2.22), where the density $\rho$ is not present, since we do not have variation of density, we have

$$
\mathscr{M}=c_{1} \mathrm{e}^{-(1 / 2) C_{D} a x}-\int 2 \Omega \chi_{v e} \mathscr{C}_{b} \mathscr{F}_{1} x^{\phi} \alpha_{e} \mathscr{F}_{2} x^{\psi} \mathrm{d} x .
$$

Making (2.52) non-dimensional for reasons that will be clear afterwards, (2.52) becomes

$$
\mathfrak{M}=\mathfrak{c}_{1} \mathrm{e}^{-(1 / 2) C_{D} \mathfrak{a x}}-\int 2 \mathfrak{D} \chi_{v e} \mathscr{C}_{b} \mathfrak{F}_{1} \mathfrak{F}^{\phi} \alpha_{e} \mathfrak{F}_{2} \mathfrak{k}^{\psi} \mathrm{d} \mathfrak{x},
$$

where

$$
\left.\begin{array}{c}
\mathfrak{M}=\frac{\mathscr{M}}{U_{0}^{2} x_{0}}, \quad \mathfrak{x}=\frac{x}{x_{0}}, \quad \mathfrak{a}=a x_{0}, \quad \mathfrak{c}_{1}=\frac{c_{1}}{U_{0}^{2} x_{0}}, \quad \mathfrak{D}=\frac{\Omega}{U_{0} x_{0}}, \\
\mathfrak{F}_{1}=\frac{\mathscr{F}_{1}}{x_{0}}, \quad \mathfrak{F}_{2}=\frac{\mathscr{F}_{2}}{U_{0}}
\end{array}\right\}
$$

are all dimensionless. Considering $(2.54 a-g)$, the second term of the right-hand side of (2.52) can be rewritten as follows:

$$
\int-\mathfrak{c}_{1} \mathfrak{z}^{0.5-\mathfrak{C}_{2} \mathfrak{z}} \mathrm{d} \mathfrak{x} .
$$


Integral (2.55) does not have a solution, but we could expand the integrating function. Therefore, we obtain

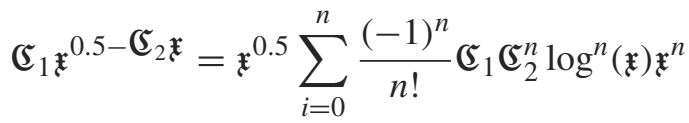

$$
\begin{aligned}
& =\mathfrak{x}^{0.5}\left(\mathfrak{S}_{1}-\mathfrak{S}_{1} \mathfrak{S}_{2} \log (\mathfrak{x}) \mathfrak{x}+\mathscr{O}(\mathfrak{x})^{2}\right) .
\end{aligned}
$$

Using a first-order approximation, (2.55) becomes

$$
\begin{aligned}
& \int-\mathfrak{x}^{0.5}\left(\mathfrak{S}_{1}-\mathfrak{S}_{1} \mathfrak{夭}_{2} \log (\mathfrak{x}) \mathfrak{x}\right) \mathrm{d} \mathfrak{x}
\end{aligned}
$$

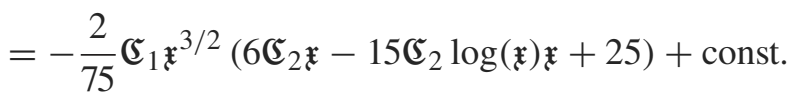

Therefore, (2.53) becomes

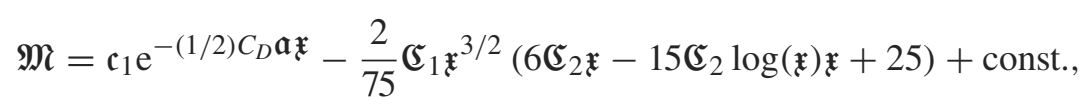

from which we can compute $\mathscr{M}$ using $(2.54 a-g)$. The structure of the first term of the right-hand side of (2.58) is similar to that proposed by Negretti et al. (2006) and Mossa \& De Serio (2016). Equation (2.58) shows an interesting result, since a pure plane jet in a rotating system does not preserve the momentum. The momentum decrease depends both on the Rossby number, i.e. the rotation, and, in the case of obstructed flows, also on characteristics of the rods. In the case of unobstructed flows, the first term of the right-hand side of (2.58) is not present.

\subsection{Jet centreline}

As shown by Bradbury (1965), the sum of the first two terms of (2.8) is very small and, therefore, can be neglected, affording

$$
0=-\frac{1}{\rho} D_{y}-2 \Omega u-\frac{U_{b}^{2}}{\frac{\mathrm{d} x}{\mathrm{~d} \alpha}}
$$

where $\alpha$ is the central angle of the circumference arc to which the curvilinear segment $\mathrm{d} x$ is approximated.

Analysing the trajectory where $u=u_{m}$, called the jet centreline, using (2.6) for $D_{y}$ and assuming $U_{b}^{2}=C_{u} u_{m}^{2}$, we have

$$
\frac{\mathrm{d} \alpha}{\mathrm{d} x}=-\frac{1}{\rho} \frac{\frac{1}{2} \rho C_{D} a V^{2}}{\left(C_{u} u_{m}^{2}\right)}-2 \frac{\Omega}{C_{u} u_{m}}
$$

where $C_{u}$ is a dimensionless coefficient and $V$ is a velocity scale normal to the jet axis in each cross-section which can be assumed to be equal to

$$
V^{2}=C_{v} \alpha_{e}^{2} u_{m}^{2}
$$


with $C_{v}$ an empirical coefficient. Therefore, using the second equation of (2.25) and (2.48), we obtain

$$
\frac{\mathrm{d} \alpha}{\mathrm{d} x}=-\frac{1}{2} \frac{C_{D} a C_{v} \alpha_{e}^{2}}{C_{u}}-2 \frac{\Omega}{C_{u} C_{u m}\left(\frac{x}{x_{0}}\right)^{-1 / 2-(1 / 4) C_{D}\left(d / s^{2}\right) x}} .
$$

Equation (2.62) can be written as follows:

$$
\frac{\mathrm{d} \alpha}{\mathrm{d}\left(\frac{x}{x_{0}}\right)}=-\frac{1}{2} \frac{x_{0} C_{D} a C_{v} \alpha_{e}^{2}}{C_{u}}-2 \frac{x_{0} \Omega}{C_{u} C_{u m}\left(\frac{x}{x_{0}}\right)^{-1 / 2-\left(x_{0} / 4\right) C_{D}\left(d / s^{2}\right)\left(x / x_{0}\right)}} .
$$

Using $\mathfrak{x}$ defined in $(2.54 a-g)$, we get

$$
\frac{\mathrm{d} \alpha}{\mathrm{d} \mathfrak{z}}=-\frac{1}{2} \frac{x_{0} C_{D} a C_{v} \alpha_{e}^{2}}{C_{u}}-2 \frac{x_{0} \Omega}{C_{u} C_{u m} \mathfrak{x}^{-1 / 2-\left(x_{0} / 4\right) C_{D}\left(d / s^{2}\right)(\mathfrak{x})}} .
$$

Rewriting (2.64) as

$$
\frac{\mathrm{d} \alpha(\mathfrak{x})}{\mathrm{d} \mathfrak{x}}=-\mathcal{A}-\frac{\mathcal{B}}{\mathfrak{x}^{-\mathcal{C} \mathfrak{x}-0.5}},
$$

with obvious meaning of the parameters $\mathcal{A}, \mathcal{B}, \mathcal{C}$, which must be obtained from the experimental data, we get the following solution:

$$
\alpha(\mathfrak{z})=-\mathcal{B} \int \mathfrak{x}^{\mathcal{C} \mathfrak{k}+1 / 2} \mathrm{~d} \mathfrak{z}-\mathcal{A} \mathfrak{x}+c_{2},
$$

where $c_{2}$ depends on the initial conditions. In the case of the absence of obstructions, i.e. $C_{D}=0,(2.66)$ reduces to

$$
\alpha(\mathfrak{z})=-\frac{2}{3} \mathcal{B}^{3 / 2}+c_{2} .
$$

Figures 6 and 7 show typical trends of the jet axis in the absence of obstructions at increasing Rossby numbers and with obstructions at increasing $C_{D} a x_{0}$, respectively. The axes of the figures have been made non-dimensional using the length scale $L_{x 0}$, defined as the maximum distance along the direction of the jet exit of the case with $R_{o}=1$ with $C_{D} a x_{0}=0$. They highlight the effects of both Coriolis and drag forces. For the paths in the figures we assumed that all the coefficients and variables are equal to 1, considering that the aim is only a comparison among different values of the Rossby number and the drag force.

\section{Model validation}

\subsection{Experimental apparatus}

The experiments were carried out using the Coriolis rotating platform at LEGI-Grenoble, France (figure 8). In this large-scale facility, experimental runs were executed by discharging a horizontal-momentum jet in an unobstructed and obstructed fluid. In the latter case a canopy made of rigid rods was used (figure 9). The LEGI tank has a diameter of $13 \mathrm{~m}$. The water depth used in the experimental runs of the present paper was equal to $0.80 \mathrm{~m}$. Figure $10(a)$ shows a sketch of the rotating platform with the jet. 


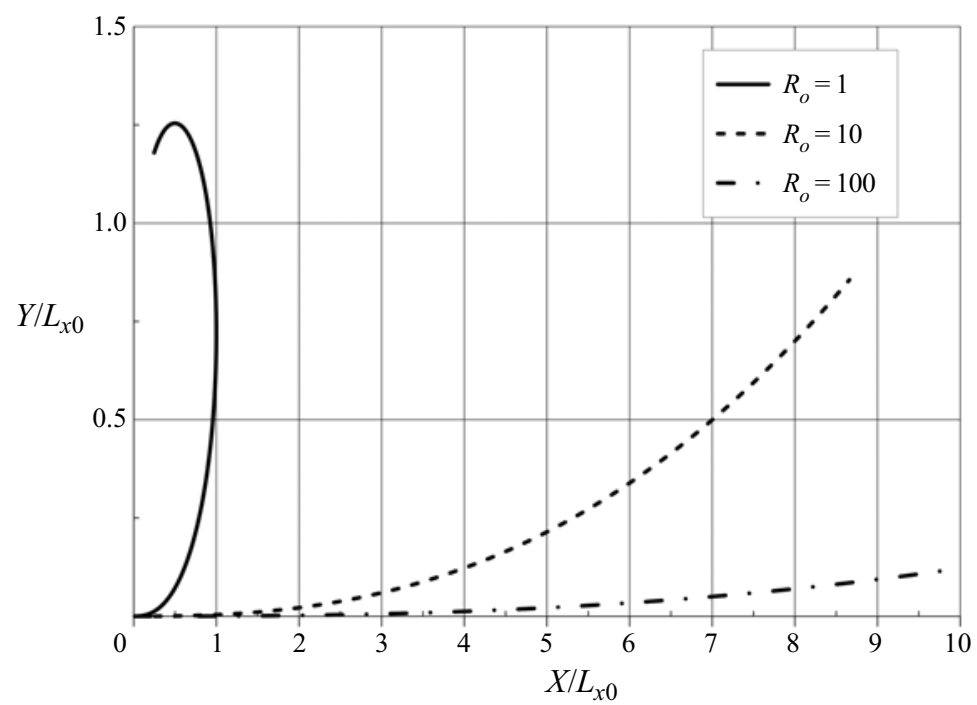

Figure 6. Comparison among jet axes without obstructions.

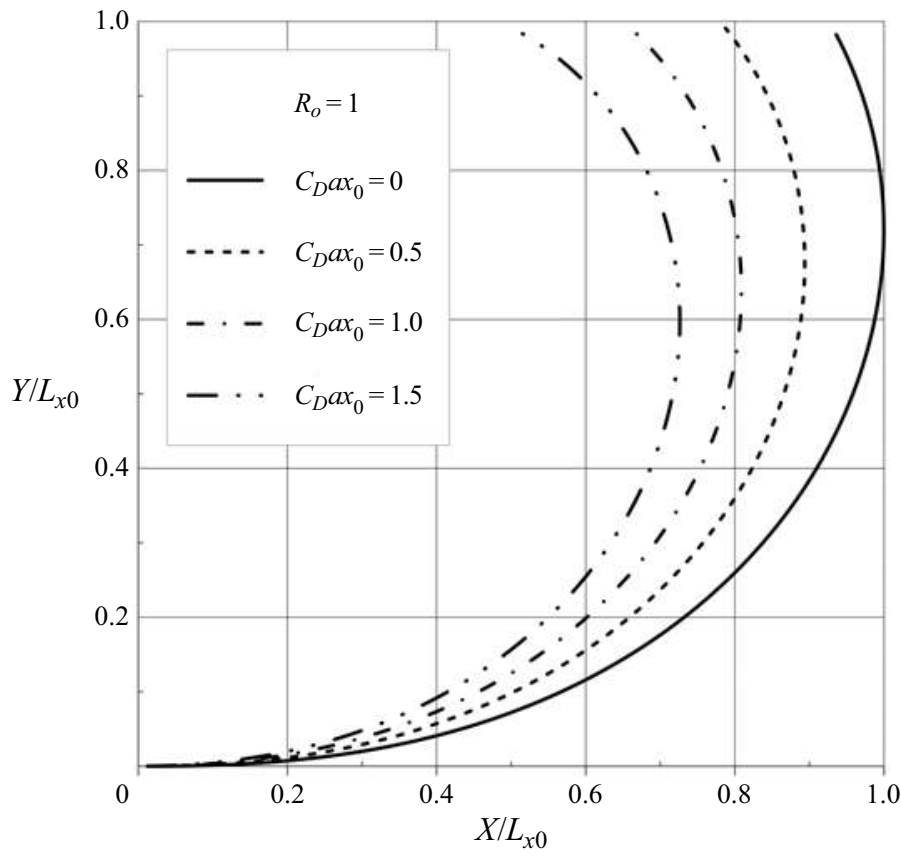

Figure 7. Comparison among centre pathlines of jets with obstructions at different values of $C_{D} a x_{0}$.

Jets were horizontally issued with a pipe, installed in the tank at a fixed depth of 0.40 $\mathrm{m}$. The jet initial diameter was equal to $0.08 \mathrm{~m}$ (inner diameter of the pipe). A specially designed rigid cylinder array was placed in the tank for the obstructed configurations. The rigid emergent cylinders were in Plexiglas, each with a diameter equal to $0.02 \mathrm{~m}$, arranged on a $2 \mathrm{~m} \times 2 \mathrm{~m}$ panel fixed at the bottom of the tank. The rods were manually mounted on the panel inside pre-drilled holes, thus ensuring a regular pattern with a centre-to-centre 


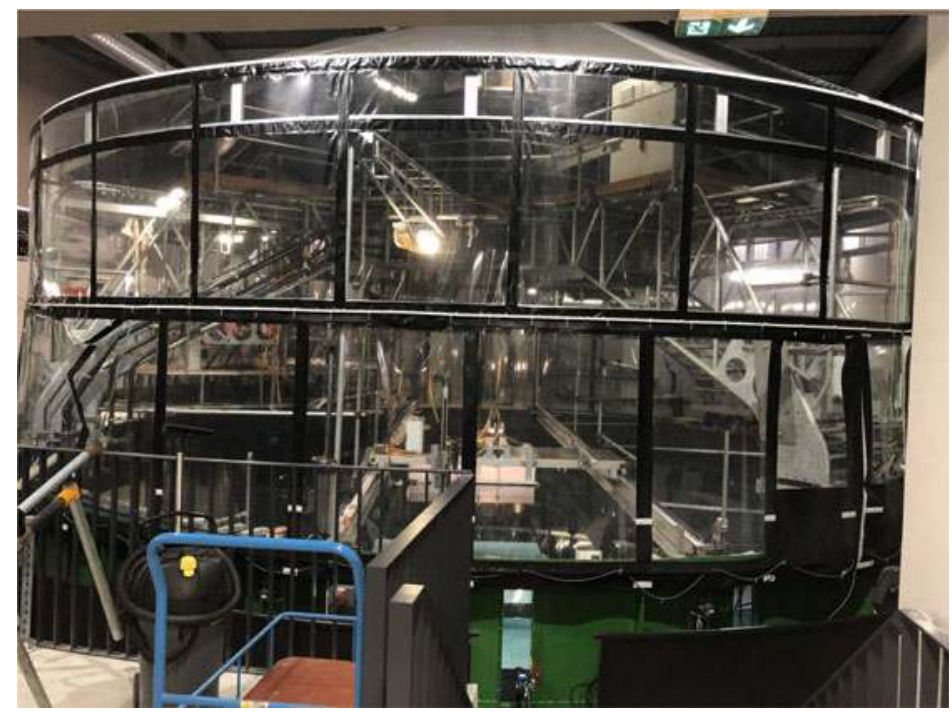

Figure 8 . The Coriolis rotating platform at LEGI.

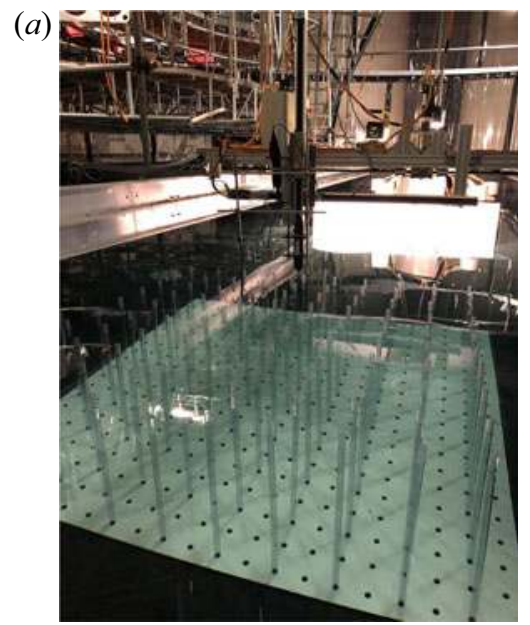

(b)

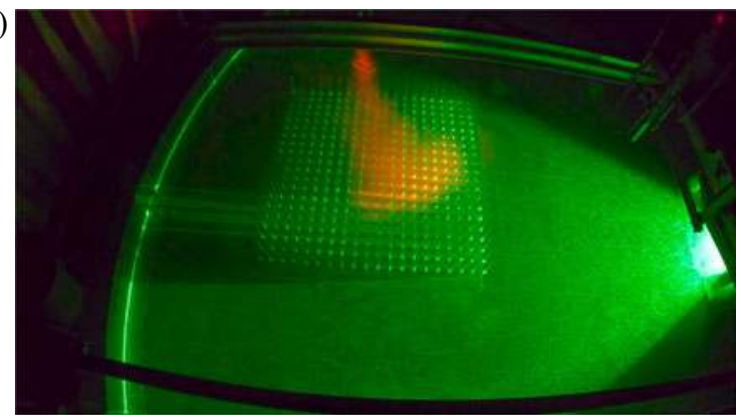

Figure 9. Experimental apparatus. (a) The stem array. (b) Jet issued in the rotating tank with stems and the PIV laser sheet.

distance $s$. The panel was placed in the tank between the carriage supports, as shown in figure $10(b)$. The centre of the jet outlet $(O)$ was $1 \mathrm{~m}$ from the upstream edge of the panel and $0.77 \mathrm{~m}$ from its external edge.

In the present paper, the runs shown in table 1 are analysed. The values of $C_{D}$ were obtained using the data of Nepf (1999). The Reynolds number of the analysed jets, based on $(2.5 a, b)$, was equal to $91 \times 10^{3}$, ensuring fully turbulent flows.

The instantaneous measurements of the velocity field at the horizontal plane passing from the centre of the jet nozzle were assessed using a particle image velocimetry (PIV) system (figure 9b). The laser source of the PIV system was mounted in the centre of the tank. Three synchronized recording cameras were mounted on the top of the tank. A continuous YAG laser (532 nm wavelength) with a power of $25 \mathrm{~W}$ and a Powell prism 

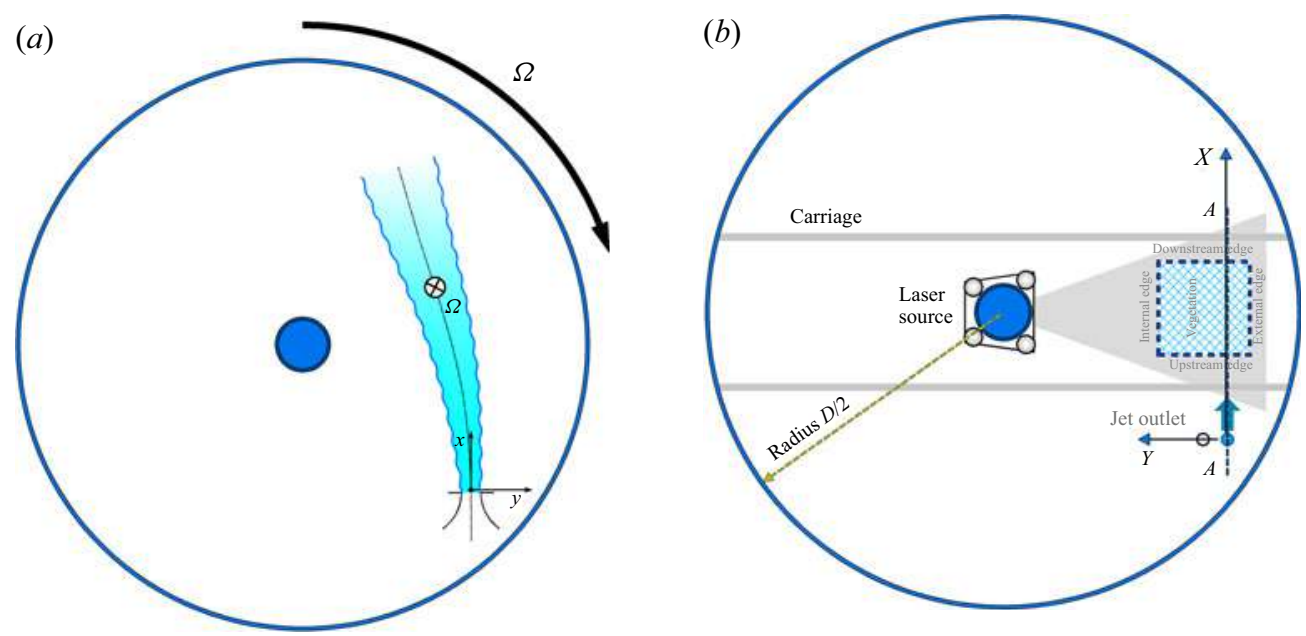

Figure 10. Sketch of the experimental apparatus. (a) Plan view of the rotating platform with the unbounded jet-like flow. $(b)$ Sketch of the location of jet outlet and vegetation panel in the rotating tank (plan view).

$\begin{array}{lccccc}\text { Run } & s(\mathrm{~m}) & C_{D} & a\left(\mathrm{~m}^{-1}\right) & a d & R_{o} \\ \text { EXP15 } & \text { No obstruction } & - & - & - & 5.12 \\ \text { EXP19 } & 0.20 & 0.7 & 0.50 & 0.01 & 6.74 \\ \text { EXP23 } & 0.10 & 0.4 & 2.00 & 0.04 & 8.19\end{array}$

Table 1. Values of some parameters of the analysed runs.

producing a $5 \mathrm{~mm}$ thick laser sheet were used. The laser sheet, set in a horizontal plane, spanned an area of more than $3 \mathrm{~m} \times 3 \mathrm{~m}$, with a $60^{\circ}$ opening angle. The PIV system enabled us to analyse a sufficiently large area of the rotating tank. Its acquisition frequency $(33 \mathrm{~Hz})$ was appropriately selected in order to avoid possible effects of disturbances of the free-surface deformations on the measurements. Furthermore, Orgasol neutrally buoyant particles with a $60 \mu \mathrm{m}$ diameter were used to seed the flow. For the processing of the experimental results, custom Matlab scripts have been developed. To account for possible optical distortion due to the presence of the water-air interface, a spatial calibration was applied to all processed images.

Figures 11 and 12 show a comparison between the model and the experiential results for the length scale $b$ and velocity scale $u_{m}$, respectively. The comparison between theoretical and experimental results shows that the developed model describes the empirical data very well, at least for the examined experiential set-up. Table 2 lists the values of the coefficients of the theoretical laws for the analysed zones of each experimental run. The analysed zones were identified on the basis of the criteria indicated above.

Figure 13 shows a comparison between the modelled and experimental values of the momentum flux. The figure shows that the momentum deficit predicted by the new model is in very good agreement with the empirical data.

Finally, model predictions of the jet axis path are validated against those obtained in the experiments (figure 14). Table 3 lists the relevant coefficients of equations (2.66) and (2.67) for each of the analysed experimental runs. The results demonstrate the ability of 


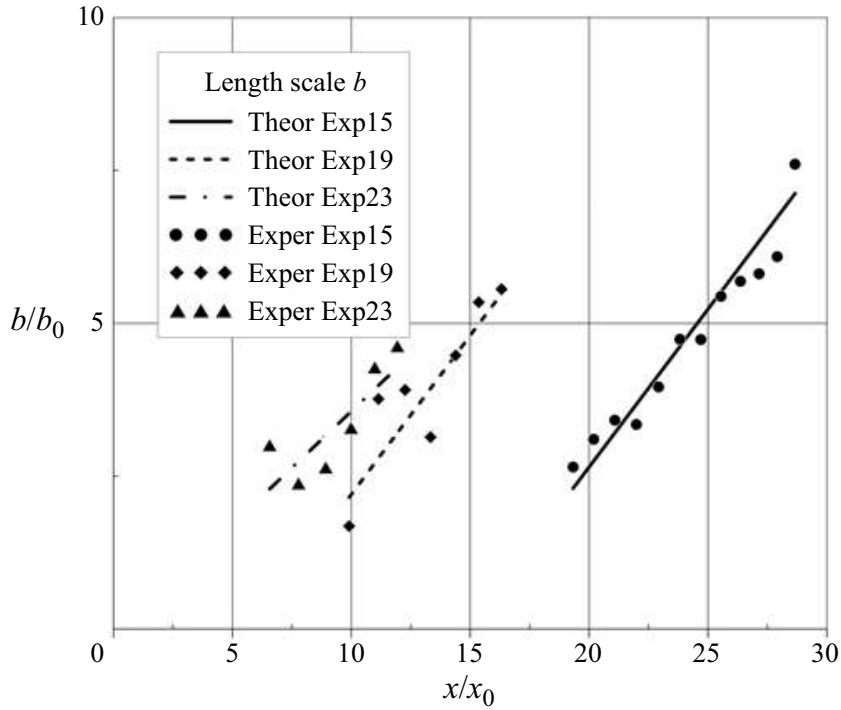

Figure 11. Comparison between theoretical and experimental values of $b$.

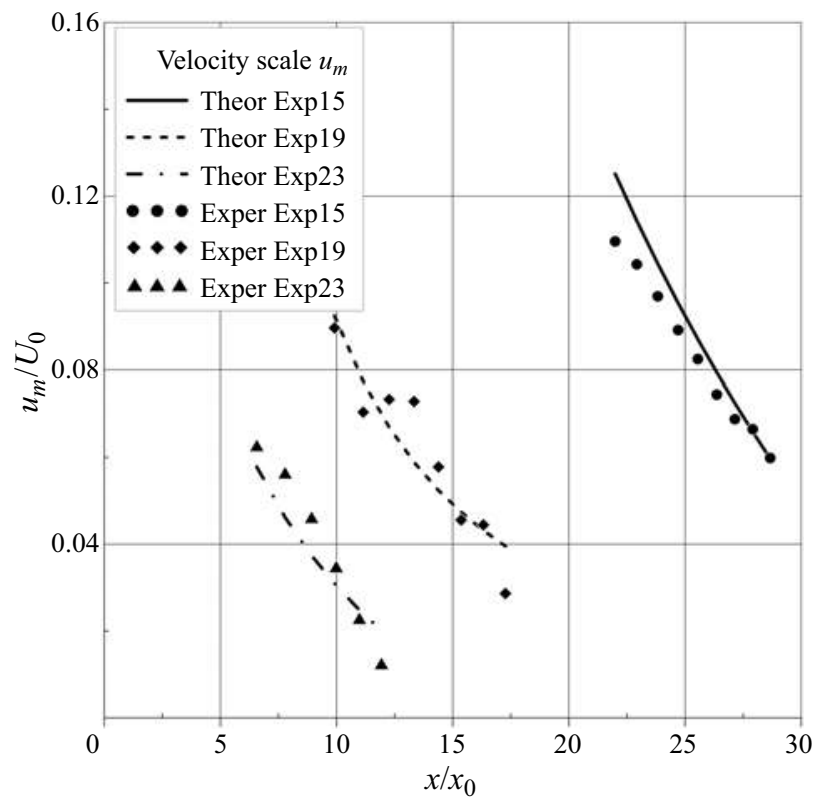

Figure 12. Comparison between theoretical and experimental values of $u_{m}$.

\begin{tabular}{lcccr} 
Run & $C_{1}$ & $C_{2}$ & $C_{3}$ & \multicolumn{1}{c}{$C_{4}$} \\
EXP15 & 0.51 & -7.69 & 2.82 & -0.46 \\
EXP19 & 0.52 & -3.00 & 3.00 & 0.01 \\
EXP23 & 0.37 & -0.14 & 0.38 & -0.05
\end{tabular}

Table 2. Values of the parameters of (2.49) and (2.50). 


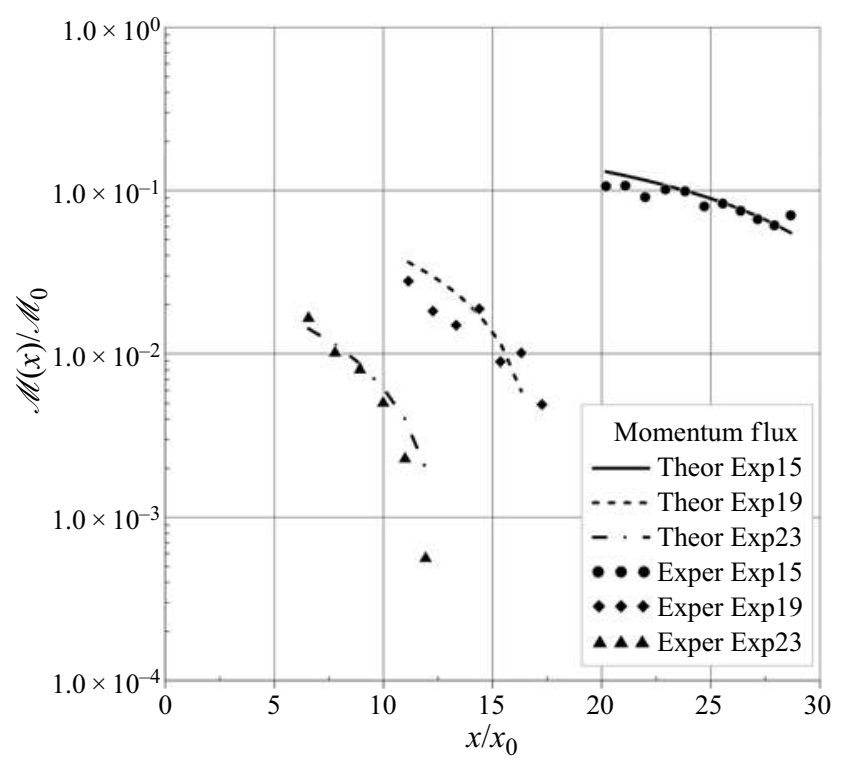

Figure 13. Comparison between theoretical and experimental values of $\mathscr{M}$.

$\begin{array}{lccc}\text { Run } & \mathcal{A} & \mathcal{B} & \mathcal{C} \\ \text { EXP15 } & 0.0 & -0.00574 & 0.000 \\ \text { EXP19 } & -1.7024 \times 10^{-5} & -0.00559 & 0.007 \\ \text { EXP23 } & -1.5600 \times 10^{-5} & -0.00538 & 0.016\end{array}$

Table 3. Values of the parameters of (2.66) and (2.67).

the model to accurately predict the jet trajectory, accounting for the effects of rotation and obstruction drag forces.

\section{Conclusions}

This paper investigates the behaviour of a plane jet-like flow in quasi-geostrophic condition issued in an obstructed flow field. Starting from the fundamental principles of mass conservation and momentum balance, the laws of variation of the jet momentum, length scale, velocity scale and centre pathline are derived. In particular, the presented solution shows that (i) the jet length scale $b$ varies linearly with the distance from the jet nozzle and (ii) the jet velocity scale $u_{m}$ decrease is a function of both the distance from the jet nozzle and the main parameters of the obstructions. The momentum deficit has been theoretically derived, concluding that its decay depends on the main parameters of the Coriolis and drag forces. Particularly, the momentum exhibits an exponential decay along the jet axis. Furthermore, an analytical model of the jet centre pathline has also been derived. The presented solutions show that the velocity scale and momentum decrease faster in the case of obstructed flows. Under the conditions of applicability described in the paper, these analytical solutions have been compared with some experimental data obtained using the Coriolis rotating platform at LEGI-Grenoble (France), showing a good agreement. 

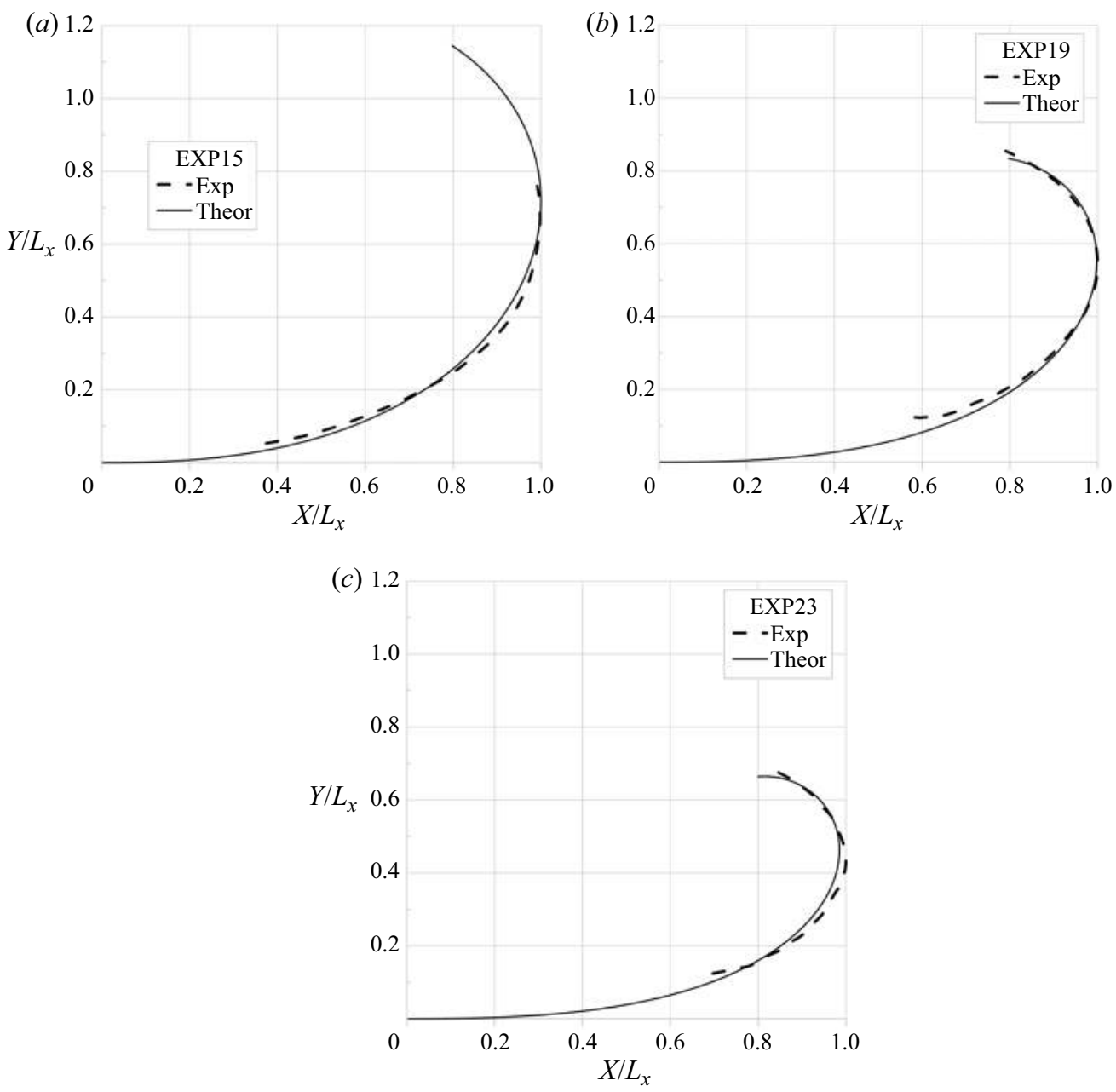

Figure 14. Comparison between theoretical and experimental jet centre pathline. (a) Case of run EXP15. (b) Case of run EXP19. (c) Case of run EXP23.

Funding. The experiments received funding from the European Union's Horizon 2020 research and innovation programme under grant agreement no. 654110, HYDRALAB+. The LEGI staff and the H+-CNRS-06-JEVERB team are gratefully acknowledged.

Declaration of interests. The authors report no conflict of interest.

Data availability statement. The data that support the findings of this study are openly available in Zenodo at https://zenodo.org/record/4543130.

\section{Author ORCIDs.}

(3) Michele Mossa https://orcid.org/0000-0002-6477-8714;

Roni H. Goldshmid https://orcid.org/0000-0001-9095-3259;

D Dan Liberzon https://orcid.org/0000-0003-4061-8203;

D M. Eletta Negretti https://orcid.org/0000-0002-8147-6718;

Joel Sommeria https://orcid.org/0000-0001-7165-2282;

Donatella Termini https://orcid.org/0000-0003-3243-7103;

Francesca De Serio https://orcid.org/0000-0002-2326-9841. 


\section{REFERENCES}

Albayrak, I., Nikora, V., Miler, O. \& O'Hare, M. 2011 A flow-plant interactions at a leaf scale: effects of leaf shape, serration, roughness and flexural rigidity. Aquat. Sci. 74 (2), 267-286.

ANTONIA, R.A. \& BILGER, R.W. 1973 An experimental investigation of an axisymmetric jet in a coflowing air steam. J. Fluid Mech. 61 (4), 805-822.

Barile, S., De Padova, D., Mossa, M. \& Sibilla, S. 2020 Theoretical analysis and numerical simulations of turbulent jets in a wave environment. Phys. Fluids 32, 035105.

Ben Meftah, M. \& Mossa, M. 2016 A modified log-law of flow velocity distribution in partly obstructed open channels. Environ. Fluid Mech. 16, 453-479.

BRADBURY, L.J.S. 1965 The structure of a self-preserving turbulent plane jet. J. Fluid Mech. 23 (1), 31-64.

De Serio, F., Ben Meftah, M., Mossa, M. \& Termini, D. 2018 Experimental investigation on dispersion mechanisms in rigid and flexible vegetated beds. Adv. Water Resour. 120, 98-113.

Fagherazzi, S., Edmonds, D.A., Nardin, W., Leonardi, N., Canestrelli, A., Falcini, F., Jerolmack, D.J., Mariotti, G., Rowland, J.C. \& Slingerland, R.L. 2015 Dynamics of river mouth deposits. Rev. Geophys. 533, 31-64.

Fischer, H.B., List, E.J., Koh, R.C.Y., Imberger, J. \& Brooks, N.H. 1979 Mixing in Inland and Coastal Waters. Academic.

GADGIL, S. 1971 Structure of jets in rotating systems. J. Fluid Mech. 47 (3), 417-436.

Giger, M., Dracos, T. \& JiRKA, G.H. 1991 Entrainment and mixing in plane turbulent jets in shallow water. J. Hydraul. Res. 29 (5), 615-642.

GoertLeR, H. 1942 Berechnung von Aufgaben der freien Turbulenz auf Grund eines neuen Naherungsansatzes. Z. Angew. Math. Mech. 22, 244-254.

JiRKA, G.H. 1994 Shallow jets. In Recent Research Advances in the Fluid Mechanics of Turbulent Jets and Plumes (ed. P.A. Davies \& M.J.V. Neves). NATO ASI Series (Series E: Applied Sciences), vol. 255. Springer.

Kaimal, J. \& Finnigan, J. 1994 Atmospheric Boundary Layer Flows: Their Structure and Momentum. Oxford University Press.

Kemp, J., HARPER, D. \& Crosa, G. 2000 The habitat-scale ecohydraulics of rivers. Ecol. Engng 16, 17-29.

Lin, G. \& ATKinson, J.F. 1999 A mechanism for offshore transport across the Gulf Stream. J. Phys. Oceanogr. 30, 226-232.

MAHESH, K. 2013 The interaction of jets with crossflow. Annu. Rev. Fluid Mech. 45 (1), 379-407.

MAROIS, D.E. \& MiTSCH, W.J. 2015 Coastal protection from tsunamis and cyclones provided by mangrove wetlands - a review. Intl J. Biodiversity Sci. 11 (1), 71-83.

Mossa, M. \& De Serio, F. 2016 Rethinking the process of detrainment: jets in obstructed natural flows. Sci. Rep. 6, 39103.

Mossa, M., Ben Meftah, M., De Serio, F. \& Nepf, H.M. 2017 How vegetation in flows modifies the turbulent mixing and spreading of jets. Sci. Rep. 7, 6587.

Negretti, M.E., Vignoli, G., Tubino, M. \& Brocchini, M. 2006 On shallow-water wakes: an analytical study. J. Fluid Mech. 567, 457-475.

Nikora, N., Nikora, V. \& O'Donoghue, T. 2013 Velocity profiles in vegetated open-channel flows: combined effects of multiple mechanisms. ASCE J. Hydraul. Engng 139 (10), 1021-1032.

NEPF, H.M. 1999 Turbulence and diffusion in flow through emergent vegetation. Water Resour. Res. 35 (2), 479-489.

PoPe, S.B. 2000 Turbulent Flows. Cambridge University Press.

Rajaratnam, N. 1976 Turbulent Jets. Elsevier Scientific Publishing Company.

Smith, S.H. \& Mungal, M.G. 1998 Mixing, structure and scaling of the jet in crossflow. J. Fluid Mech. $357,183-122$.

TANinO, Y. \& NEPF, H.M. 2008 Lateral dispersion in random cylinder arrays at high Reynolds number. J. Fluid Mech. 600, 339-371.

TenneKes, H. \& LumLey, J.L. 1972 A First Course in Turbulence. MIT.

Thomas, P.J. \& Linden, P.F. 2007 Rotating gravity currents: small-scale and large-scale laboratory experiments and a geostrophic model. J. Fluid Mech. 578, 35-65.

White, B.L. \& NEPF, H.M. 2003 Scalar transport in random cylinder arrays at moderate Reynolds number. J. Fluid Mech. 487, 43-79.

White, B.L. \& NePF, H.M. 2007 Shear instability and coherent structures in a flow adjacent to a porous layer. J. Fluid Mech. 593, 1-32.

White, B.L. \& NePF, H.M. 2008 A vortex-based model of velocity and shear stress in a partially vegetated shallow channel. Water Resour. Res. 44 (1), W01412. 